\title{
Enhanced Inhibition of Synaptic Transmission by Dopamine in the Nucleus Accumbens during Behavioral Sensitization to Cocaine
}

\author{
Corinne Beurrier and Robert C. Malenka \\ Nancy Pritzker Laboratory, Department of Psychiatry and Behavioral Sciences, Stanford University School of Medicine, \\ Palo Alto, California 94304
}

\begin{abstract}
Neural adaptations in the nucleus accumbens (NAc), a key component of the mesolimbic dopamine (DA) system, are thought to mediate several of the long-term behavioral sequelas of chronic in vivo exposure to drugs of abuse. Here, we examine whether the modulation of excitatory synaptic transmission by DA in the NAc shell is modified after chronic cocaine exposure that induced behavioral sensitization. The DAinduced inhibition of AMPA receptor-mediated synaptic responses was enhanced in cocaine-treated mice, an effect that was caused by activation of D1-like receptors. DA did not
\end{abstract}

enhance NMDA receptor-mediated synaptic responses in saline- and cocaine-treated mice or in the dorsal striatum of control mice. We hypothesize that the enhanced inhibitory effects of DA on synaptic transmission in the NAc are one of a number of adaptations that contribute to a decrease in excitatory drive to NAc after exposure to drugs of abuse.

Key words: addiction; cocaine; dopamine; nucleus accumbens; striatum; synaptic transmission; glutamate; AMPA receptors; NMDA receptors
The reinforcing effects of drugs of abuse are thought to be mediated in part by the release of dopamine (DA) in the mesolimbic dopaminergic pathway, which projects from A10 dopaminergic cell bodies within the ventral tegmental area to the nucleus accumbens (NAc) (Wise, 1998). Thus, critical questions for understanding the neural mechanisms responsible for mediating the behavioral effects of drugs of abuse include (1) what are the effects of DA on synaptic transmission in the NAc and (2) how are these effects modified by chronic in vivo exposure to drugs of abuse? GABAergic medium spiny neurons are the major cell type in the NAc and receive glutamatergic inputs from cortical and subcortical limbic areas, including the hippocampus, prefrontal cortex, and amygdala (Groenewegen et al., 1999; Nicola et al., 2000). Because these cells display very negative resting potentials (Higashi et al., 1989; Uchimura and North, 1991), they are highly dependent on these excitatory inputs to generate their outputs. DA, as well as psychostimulants such as amphetamine, depresses synaptic transmission at these excitatory synapses via activation of a D1-like receptor, although the exact mechanism by which this occurs is contentious (Higashi et al., 1989; Pennartz et al., 1992; Harvey and Lacey, 1996, 1997; Nicola et al., 1996; Nicola and Malenka, 1997). Here, we examine how the modulation of excitatory synaptic transmission in the NAc by DA is modified after chronic in vivo cocaine administration sufficient to elicit behavioral sensitization, a prominent animal model for certain core features of addiction (Robinson and Berridge, 1993; Wolf, 1998; Vanderschuren and Kalivas, 2000).

Received March 29, 2002; revised May 1, 2002; accepted May 7, 2002.

This work was supported by grants from Fondation pour la Recherche Médicale (C.B.) and the National Institute on Drug Abuse (R.C.M.). We thank A. Bonci, D. Saal, and M. Thomas for helpful comments.

Correspondence should be addressed to Robert C. Malenka, Department of Psychiatry and Behavioral Sciences, 1201 Welch Road, Room P105, Stanford Medical Center, Palo Alto, CA 94304. E-mail: malenka@stanford.edu.

Copyright (C) 2002 Society for Neuroscience $0270-6474 / 02 / 225817-06 \$ 15.00 / 0$

\section{MATERIALS AND METHODS}

Treatment regimen and locomotor activity. Male C57BL/6 mice $(22 \mathrm{~d})$ were given intraperitoneal injections of either saline $(0.9 \% \mathrm{NaCl})$ or saline with cocaine $(15 \mathrm{mg} / \mathrm{kg})$. Immediately after each injection, horizontal locomotor activity was monitored in open-field chambers (Med Associates Inc., St. Albans, VT) for $15 \mathrm{~min}$. After an initial $2 \mathrm{~d}$ of receiving only saline injections, mice were randomly divided into groups that received five daily injections of either cocaine or saline. After 10-14 $\mathrm{d}$ without injections, both groups received cocaine injections, and locomotor activity was assessed. Brain slices were prepared from these animals on the following day. Some of these animals (10 of 31 saline animals; 10 of 43 cocaine animals) were included in our previous study on behavioral sensitization (Thomas et al., 2001).

Electrophysiology. Sagittal slices of the NAc $(200-250 \mu \mathrm{m})$ were prepared as described previously (Thomas et al., 2001). After a $1 \mathrm{hr}$ recovery period, slices were placed in a submersion-type recording chamber and perfused $(1.5-2 \mathrm{ml} / \mathrm{min})$ at room temperature with a bicarbonatebuffered solution (artificial CSF) saturated with $95 \% \mathrm{O}_{2} / 5 \% \mathrm{CO}_{2}$ and containing (in mM): $119 \mathrm{NaCl}, 2.5 \mathrm{KCl}, 1 \mathrm{NaH}_{2} \mathrm{PO}_{4}, 1.3 \mathrm{MgCl}_{2}, 2.5$ $\mathrm{CaCl}_{2}, 26.2 \mathrm{NaHCO}_{3}, 11$ glucose, and 0.1 picrotoxin.

Cells were visualized with an upright microscope (Zeiss, Thornwood, NY), and whole-cell voltage-clamp recordings were made using an Axopatch 1D amplifier (Axon Instruments, Foster City, CA). Electrodes (5-8 M $\Omega$ ) contained (in $\mathrm{mm}$ ): 117 cesium gluconate, $2.8 \mathrm{NaCl}, 20$ HEPES, 0.4 EGTA, 5 TEA-Cl, $2.5 \mathrm{MgATP}$, and 0.25 MgGTP, pH 7.2-7.4 (285-295 mOsm). Field potential recordings were made using pipettes filled with $1 \mathrm{~m} \mathrm{NaCl}$. For perforated-patch experiments, amphotericin B $(30 \mathrm{mg} / \mathrm{ml})$ dissolved in DMSO was added to internal solution (0.02-0.03\% final concentration) containing (in mM): 110 cesium gluconate, $2.8 \mathrm{NaCl}$, 20 HEPES, 0.4 EGTA, 5 TEA-Cl, and $20 \mathrm{CsCl}$. Experiments were begun only after series resistance had stabilized. Medium spiny neurons were identified by their morphology and high resting membrane potential $(-75$ to $-85 \mathrm{mV})$ as monitored at break-in.

Stainless steel bipolar microelectrodes were placed at the prelimbic cortex-NAc border to stimulate afferents, preferentially from the prelimbic cortex at a baseline frequency of $0.1 \mathrm{~Hz}$. Neurons were voltage clamped at a membrane potential of $-80 \mathrm{mV}$. Series and input resistances were determined with each afferent stimulus and were monitored for stability throughout each experiment. Data were filtered at $2 \mathrm{kHz}$, digitized at $5 \mathrm{kHz}$, and collected on-line using custom software (Igor Pro; Wavemetrics, Lake Oswego, OR). Evoked response amplitudes were calculated by taking the mean of a $1 \mathrm{msec}$ window around the peak and 


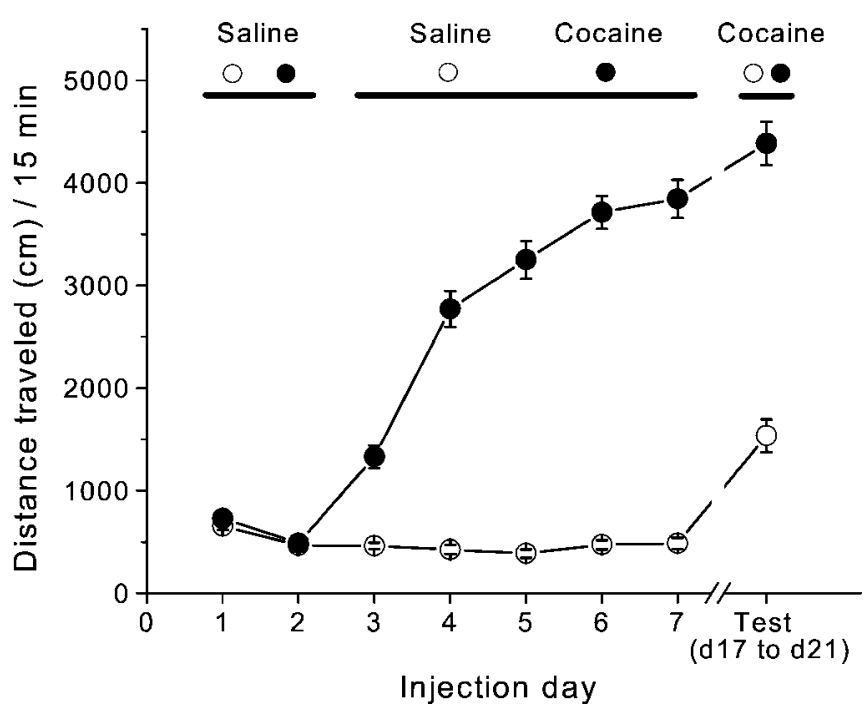

Figure 1. Repeated cocaine administration induces behavioral sensitization. Mean \pm SEM acute locomotor activity in response to saline and cocaine injections is shown. Locomotor activity was monitored for $15 \mathrm{~min}$ immediately after each injection.

comparing this with the mean of an $8 \mathrm{msec}$ window immediately before the stimulation artifact. To simultaneously monitor AMPA receptor (AMPAR) and NMDA receptor (NMDAR) EPSCs, cells were rapidly depolarized to $+40 \mathrm{mV}$ and held for 1-3 min before beginning afferent stimulation to allow voltage-dependent conductances to inactivate completely. AMPAR EPSCs were measured on the rising phase of the EPSCs at a time point that was minimally affected $(<10 \%)$ by application of D-APV, on average $6.1 \mathrm{msec}(n=32)$ after the simulation artifact (see Fig. 4A). The NMDAR EPSC was measured $250 \mathrm{msec}$ after the stimulation artifact, a time at which there was no AMPAR-mediated component. AMPAR/NMDAR ratios were calculated by averaging 10-20 consecutive responses immediately before or at the end of DA application and making measurements as described above. The data in Figure 2 were collected and analyzed in a blind manner. Results are presented as mean \pm SEM. Statistical significance was assessed using two-tailed Student's $t$ tests. Traces in figures have had stimulus artifacts removed and are the average of 10-20 consecutive responses.

Drugs. All drugs were purchased from Sigma-RBI (St. Louis, MO) except cocaine hydrochloride (Stanford Health Services Pharmacy, Palo Alto, CA) and D-APV (Tocris Cookson, Ballwin, MO). Stock solutions of dopamine hydrochloride, $R(+)$-7-chloro-8-hydroxy-3-methyl-1-phenyl2,3,4,5-tetrahydro-1H-3-benzazepine hydrochloride [R(+)-(+)-SCH-23390], 1-[2-(bis[4-fluorophenyl]methoxy)ethyl]-4-(3-phenylpropyl)piperazinedihydrochloride (GBR-12909), and cocaine hydrochloride were made in water and applied through the superfusion medium. Sodium metabisulfite (final concentration, $50 \mu \mathrm{M}$ ) was added to the dopamine solution. Cocaine for in vivo injections was dissolved in $\mathrm{NaCl}(0.9 \%)$.

\section{RESULTS}

\section{Long-lasting locomotor sensitization to cocaine in mice}

To induce behavioral sensitization, we paired repeated cocaine injections with exposure of the animals to a distinct test environment. After $2 \mathrm{~d}$ of saline injections to habituate the animals to the activity box, the locomotor response to a fixed dose of cocaine (15 $\mathrm{mg} / \mathrm{kg}$ ) increased dramatically across days of testing (Fig. 1) (day 3 distance traveled: saline, $463.5 \pm 31.1 \mathrm{~cm}, n=31$; cocaine, $1329.5 \pm 111.1 \mathrm{~cm}, n=43$; day 7 distance traveled: saline, $484.6 \pm$ $54.8 \mathrm{~cm}, n=31$; cocaine, $3843.9 \pm 185.5 \mathrm{~cm}, n=43 ; p<0.0001)$. To test whether this procedure produced long-lasting locomotor sensitization, we administered a challenge dose of cocaine to both saline- and cocaine-treated groups 10-14 d after the last dose of the initial treatment regimen. Mice pretreated with cocaine showed a much greater locomotor response to cocaine than did saline-pretreated animals (Fig. 1) (cocaine, $4384.9 \pm 212.8 \mathrm{~cm}$, $n=43$; saline, $1535.3 \pm 159.1 \mathrm{~cm}, n=31 ; p<0.0001)$. These results indicate that the initial $5 \mathrm{~d}$ exposure to cocaine caused behavioral sensitization that lasted for $\geq 2$ weeks.

\section{Increased inhibition of excitatory synaptic transmission by dopamine in sensitized mice}

The NAc is commonly divided into two components, the shell and the core, which can be distinguished both anatomically and functionally (Zahm, 1999). Previous work found modification of excitatory synaptic transmission after chronic cocaine treatment in the shell but not in the core of the NAc (Thomas et al., 2001). Therefore, all recordings were made in the NAc shell. In initial experiments, we used whole-cell recordings to monitor AMPARmediated EPSCs (AMPAR EPSCs) and applied a concentration of DA $(75 \mu \mathrm{M})$ that reliably elicits a depression of synaptic transmission in the NAc (Nicola et al., 1996). We found that there was no difference between slices from saline- and cocaine-treated mice at the end of the $10 \mathrm{~min}$ DA application (Fig. 2A,D) (cocaine, $-26.9 \pm 4 \%$ change from initial baseline, $n=12$; saline, $-25.8 \pm 3.7 \%, n=12 ; p>0.05)$. However, the effect of DA washed out much more slowly in the cocaine group (Fig. 2A) (between 5 and 11 min after washout: cocaine, $-13.7 \pm 4.8 \%, n=$ 12 ; saline, $1.7 \pm 4 \%, n=12 ; p<0.05)$. Because slices are exposed to concentrations of DA $<75 \mu \mathrm{M}$ during the washout, this difference in washout rate may reflect the fact that lower concentrations of DA had a greater effect in cocaine-treated mice. To test this possibility, we applied a lower concentration of DA $(20 \mu \mathrm{M})$ that had a minimal effect on slices from saline-treated mice (Fig. $2 B-D)(-3.9 \pm 4.5 \%, n=9)$. In contrast, this same concentration of DA caused a significant depression of synaptic transmission in slices from cocaine-treated animals (Fig. $2 B-D)(-19.9 \pm 4.9 \%$, $n=10, p<0.05)$. These results indicate that the chronic in vivo cocaine treatment enhanced the inhibitory actions of DA on excitatory synaptic transmission in the NAc shell.

\section{Synaptic actions of DA in cocaine-treated mice are caused by D1-like receptors}

DA receptors are commonly subdivided into two classes: (1) D1-like receptors (D1 and D5) and (2) D2-like receptors (D2, D3, and D4) (Sibley and Monsma, 1992; Civelli et al., 1993; Jarvie and Caron, 1993). The inhibition of excitatory synaptic transmission by DA in the NAc appears to be mediated primarily by a D1-like receptor (Higashi et al., 1989; Pennartz et al., 1992; Nicola et al., 1996). To address whether D1-like receptors also mediate the synaptic actions of DA after in vivo cocaine treatment, we made extracellular field potential recordings (fEPSPs) and tested the ability of the specific D1 receptor antagonist SCH-23390 $(10 \mu \mathrm{M})$ to antagonize the inhibitory actions of DA $(20 \mu \mathrm{M})$. As observed using whole-cell recordings, the inhibition of fEPSPs by DA was greater in slices from the cocaine treatment group (Fig. $3 A$ ) (cocaine, $-17.8 \pm 2.1 \%, n=28$; saline, $-5.4 \pm 2.2 \%, n=11 ; p<$ 0.01). This depressant action of DA in the cocaine group was significantly reduced by SCH-23390 (Fig. 3B) (first DA application, $-25.5 \pm 4.9 \%$; second application in the presence of $\mathrm{SCH}-$ $23390,-8.5 \pm 3.5 \% ; n=6 ; p<0.05)$, indicating that as is the case in untreated animals (Higashi et al., 1989; Pennartz et al., 1992; Nicola et al., 1996), this action of DA is mediated in large part by D1-like receptors that presynaptically depress glutamate release (Nicola et al., 1996, 2000; Nicola and Malenka, 1997).

The enhanced inhibition of excitatory transmission by DA in 


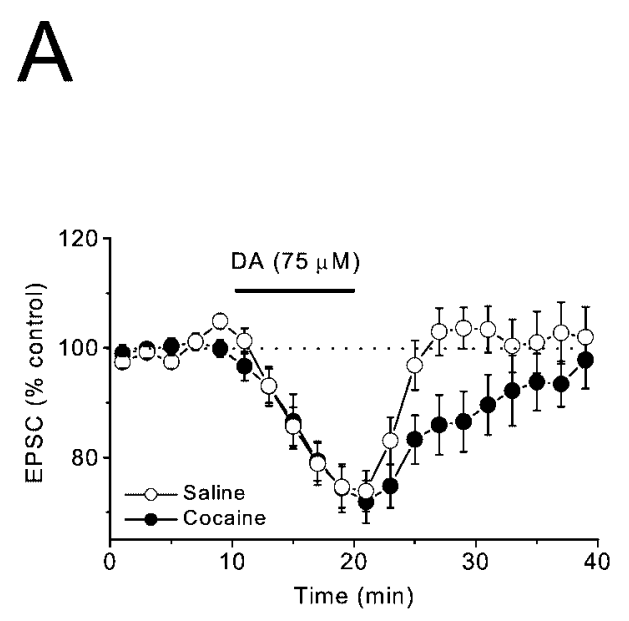

B
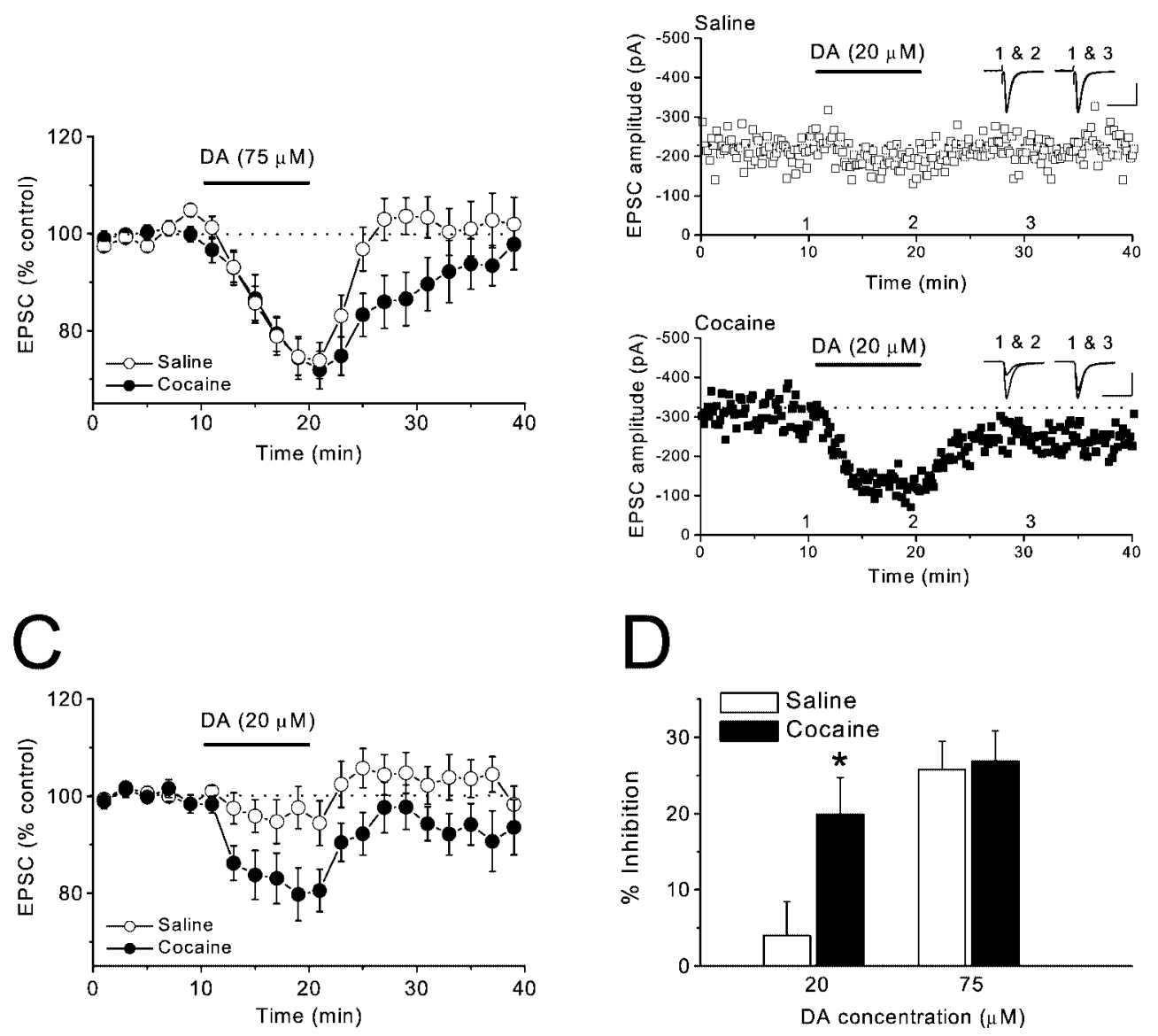

D

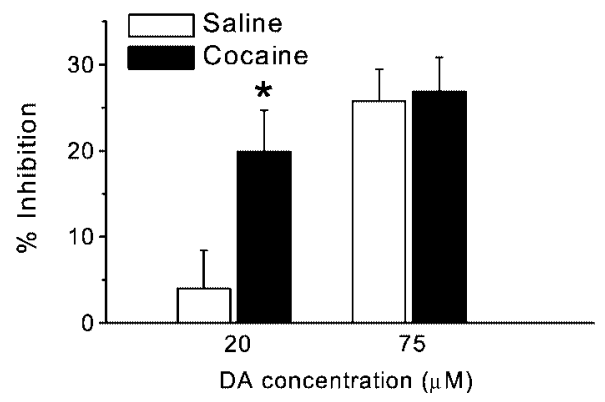

Figure 2. Chronic cocaine treatment enhances inhibitory actions of DA on AMPAR EPSCs. $A$, Summary graph of the effects of DA $(75 \mu \mathrm{M})$ in saline $(n=12$ cells, 8 mice) and cocaine-treated ( $n=12$ cells, 9 mice) mice. $B$, Sample experiments from saline (top) and cocainetreated (bottom) mice displaying the effect of $20 \mu \mathrm{M}$ DA. Sample traces were collected at the times indicated on the graph. Calibration: top, $50 \mathrm{msec}, 100 \mathrm{pA}$; bottom, $50 \mathrm{msec}, 200 \mathrm{pA}$. C, Summary graph of the effects of DA $(20 \mu \mathrm{M})$ in saline $(n=9$ cells, 7 mice $)$ and cocainetreated ( $n=10$ cells, 5 mice) mice. $D$, Magnitude of inhibition of AMPAR EPSCs by DA in saline and cocainetreated mice $(* p<0.05)$. the cocaine-treated group could be explained by some modification of the D1-like DA receptors (e.g., increase in receptor number and/or function) or by a change in the DA transporters (DATs) that might influence the effective concentration of DA when it is applied to the slices (e.g., decrease in DAT number and/or function). To help distinguish between these possibilities, we examined whether the selective DAT inhibitor GBR-12909 (300 nM) enhanced the synaptic actions of DA. If it did, it would suggest that the level of DAT activity in our slices could limit the effective concentration of DA. However, in saline-treated mice, GBR-12909 (300 nM) did not significantly affect the synaptic depression elicited by DA ( $30 \mu \mathrm{M} ; n=4$; data not shown). These results indicate that DATs do not influence the effective concentration of exogenous DA achieved in the slices. Therefore, it is very unlikely that the enhanced inhibition of excitatory synaptic transmission by DA in cocaine-treated mice is caused by a reduction in DAT number and/or function.

\section{Lack of a postsynaptic effect of DA on NMDAR-mediated EPSCs}

It has been suggested that the inhibitory effects of D1 receptor activation in the NAc are the consequence of a DA-induced enhancement of NMDAR-mediated responses (Harvey and Lacey, 1997), an action of DA that has also been reported to occur in the dorsal striatum (Cepeda et al., 1993; Levine et al., 1996). To determine whether DA modulation of NMDARmediated responses is affected by chronic in vivo cocaine treatment, we simultaneously measured the effect of DA on NMDAR- and AMPAR-mediated EPSCs by holding the cell at $+40 \mathrm{mV}$ (Fig. 4A) (see Materials and Methods). If DA, via a postsynaptic action, potentiates NMDAR-mediated EPSCs (NMDAR EPSCs) but not AMPAR EPSCs, then the presynaptic DA-induced depression of NMDAR EPSCs should be less than that for AMPAR EPSCs, and the ratio of AMPAR- to NMDAR-mediated synaptic currents should decrease during DA application. If DA has no postsynaptic effect, the AMPAR/NMDAR ratio should remain constant throughout the experiment. In slices from saline-treated mice, DA $(75 \mu \mathrm{M})$ depressed AMPAR- and NMDAR-mediated responses to the same degree (Fig. $4 B$ ) (AMPAR, $-33.7 \pm 7.6 \%$; NMDAR, $-44.8 \pm 5.4 \% ; n=8 ; p>0.05)$, as reflected by the lack of change in the AMPAR/NMDAR ratio in the presence of DA (Fig. 4E) (control, $2.9 \pm 0.56$; DA, $3.31 \pm 0.69 ; n=8 ; p>0.05$ ). We then repeated the same experiments in cocaine-treated mice to see whether this might reveal an effect of DA on NMDARmediated responses. Again, the depressant action of DA on AMPAR- and NMDAR-mediated EPSCs was not significantly different (Fig. 4B) (AMPAR, $-28.5 \pm 5.4 \%$; NMDAR, $-38.1 \pm$ $3.6 \% ; n=15 ; p>0.05)$, and no change in the AMPAR/NMDAR ratio was induced by DA (Fig. $4 E$ ) (control, $3.25 \pm 0.47$; DA, $3.68 \pm 0.53 ; n=15 ; p>0.05)$.

Although the previous work in the NAc also used standard whole-cell recording techniques (Harvey and Lacey, 1997), we were concerned that the lack of effect of DA on NMDAR EPSCs may be caused by dialysis, so-called washout of some intracellular components that are necessary for the postsynaptic effects of DA. 

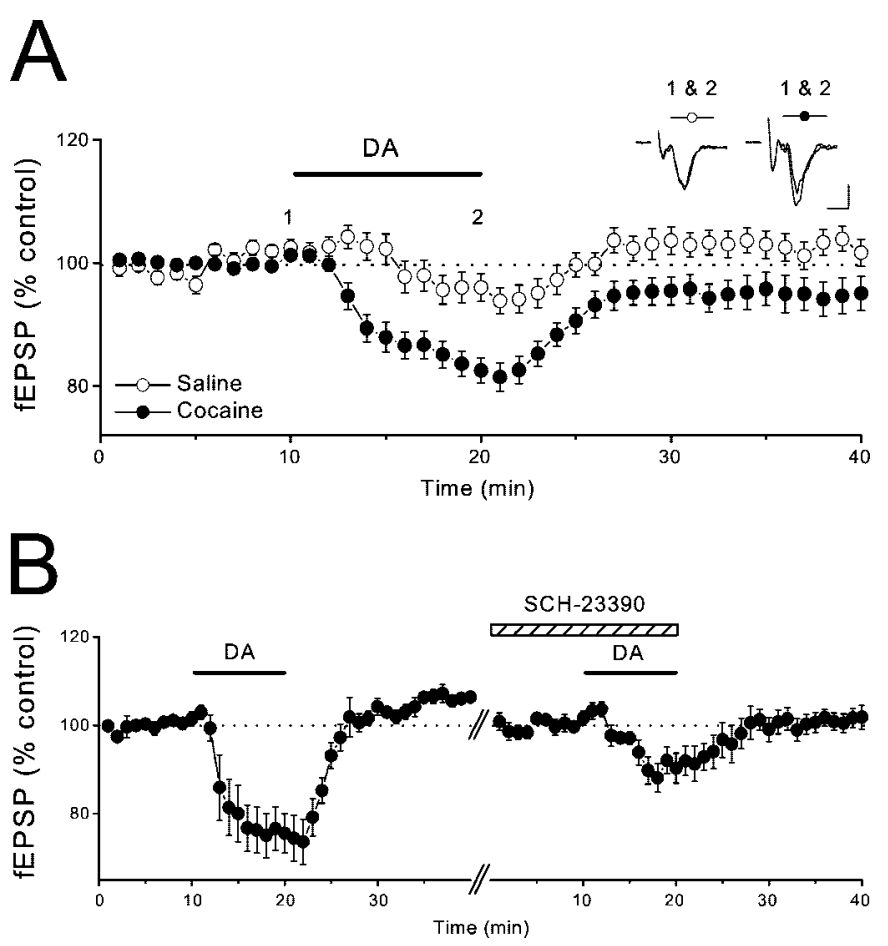

Figure 3. The DA-induced depression of excitatory synaptic transmission in cocaine-treated mice is mediated by D1-like receptors. $A$, Summary graph showing effects of DA $(20 \mu \mathrm{M})$ on field EPSPs in saline $(n=$ 11 slices, 8 mice) and cocaine-treated $(n=28$ slices, 20 mice) mice. Sample traces were collected at the times indicated on the graph. Calibration: $4 \mathrm{msec}, 0.1 \mathrm{mV}$. B, Summary of experiments in which DA $(20 \mu \mathrm{M})$ was applied to slices from cocaine-treated mice first in the absence and then in the presence of SCH-23390 (10 $\mu \mathrm{M} ; n=6$ slices, 6 mice $)$. fEPSP amplitudes were renormalized when SCH-23390 was applied to minimize possible effects of experimental drift.

Therefore, we repeated the same experiment in slices from control mice using perforated-patch recording techniques. Again, the inhibition of AMPAR- and NMDAR-mediated EPSCs induced by DA $(100 \mu \mathrm{M})$ was similar (Fig. $4 C$ ) (AMPAR, $-26.8 \pm 12.6 \%$; NMDAR, $-19.7 \pm 16.3 \% ; n=5 ; p>0.05)$, and, thus, there was no effect on the AMPAR/NMDAR ratio (Fig. 4E) (control, $2.18 \pm 0.2 ; \mathrm{DA}, 2.16 \pm 0.29 ; n=5 ; p>0.05)$. In a final attempt to determine whether DA potentiates NMDAR EPSCs, we tested its effects in the dorsal striatum, an area of the brain in which DA does not have a presynaptic action (Calabresi et al., 1987, 1995; Nicola and Malenka, 1998). Consistent with these previous results, DA $(30-75 \mu \mathrm{M})$ did not affect AMPAR EPSCs (Fig. $4 D)(-5.5 \pm 3.8 \% ; n=4)$. However, it also did not affect NMDAR EPSCs (Fig. 4D) $(-5.9 \pm 2.9 \% ; n=4)$ or the AMPAR/NMDAR ratio (Fig. $4 E$ ) (control, $1.73 \pm 0.35$; DA, $1.77 \pm 0.42 ; n=4 ; p>0.05)$. Thus, we were unable to observe any postsynaptic effect of DA on NMDAR-mediated synaptic responses in either the NAc or the dorsal striatum.

\section{DISCUSSION}

A prominent rodent model for some key features of addiction is the long-lasting increase in the acute drug-induced locomotor response after repeated exposure to psychostimulants (Robinson and Berridge, 1993; Wolf, 1998; Vanderschuren and Kalivas, 2000). This increased response, termed behavioral sensitization, is thought to reflect modifications in the mesolimbic DA system, especially in dopaminergic and glutama- tergic synaptic transmission (Wolf, 1998; Vanderschuren and Kalivas, 2000). In a previous study, we examined basal excitatory synaptic transmission in the NAc during behavioral sensitization and found that chronic in vivo cocaine exposure caused a long-lasting depression of synaptic strength in the NAc shell (Thomas et al., 2001). Here, we examine whether this same treatment protocol affects the modulation of excitatory synaptic transmission by DA. This is of particular interest because chronic psychostimulant administration appears to enhance DA release in the NAc in response to subsequent challenge injections of drug, an effect that is observed even after relatively long periods of abstinence after the initial psychostimulant administration (Robinson et al., 1988; Kalivas and Duffy, 1993; Pierce and Kalivas, 1995; White and Kalivas, 1998).

We find that the presynaptic inhibitory action of DA is enhanced in cocaine-sensitized animals, and that this effect is mediated by a D1-like receptor, as found previously in control animals (Pennartz et al., 1992; Nicola et al., 1996; but see O'Donnell and Grace, 1994). The lack of effect of GBR-12909, a DAT inhibitor, on the synaptic action of DA indicates that enhancement of the presynaptic effect of DA is probably not attributable to some downregulation of DAT activity. Instead, the change appears to be caused by a modification in the number and/or function of the presynaptic D1-like receptors. Consistent with this hypothesis is the finding that chronic cocaine administration increases the inhibitory action of D1 agonists on the single-unit responses of NAc neurons (Henry and White, 1991), and that an enhancement of the presynaptic effects of DA has also been reported after chronic treatment with methamphetamine (Higashi et al., 1989).

Because DA has been reported to enhance NMDARmediated responses in both the NAc (Harvey and Lacey, 1997) and the dorsal striatum (Cepeda et al., 1993; Levine et al., 1996), we also examined whether this action of DA is modified by chronic in vivo cocaine exposure. Surprisingly, however, we saw no effect of DA on NMDAR EPSCs in either control or sensitized mice, even when perforated-patch recording techniques were used. Furthermore, we saw no effect of DA on AMPAR or NMDAR EPSCs in the dorsal striatum. In addition to species differences (mice vs rats), one important difference between our experiments and previous ones is that we monitored the NMDAR EPSC at $+40 \mathrm{mV}$, a holding potential at which all voltage-dependent conductances are inactivated. If the enhancement of NMDAR-mediated responses observed in previous work was caused by a modulation of such conductances by DA, under our recording conditions, we would not expect to see any effect. Indeed, DA modulates a number of different voltage-dependent conductances in striatal cells (Nicola et al., 2000), and blockade of L-type $\mathrm{Ca}^{2+}$ channels eliminates the DA-induced enhancement of NMDARmediated responses in dorsal striatal cells (Cepeda et al., 1998). Therefore, we conclude that DA does not directly modulate NMDAR function in medium spiny neurons in either the NAc or dorsal striatum, although via modulation of voltagedependent conductances, DA may have important indirect effects on NMDAR-mediated currents. Because we did not examine and compare isolated NMDAR EPSCs, we cannot state whether the cocaine exposure modified the properties of NMDARs, as has been observed with chronic morphine treatment (Martin et al., 1999); e.g., dramatic cocaine-induced changes in the kinetics of the AMPAR EPSC or NMDAR 
$A_{1}$

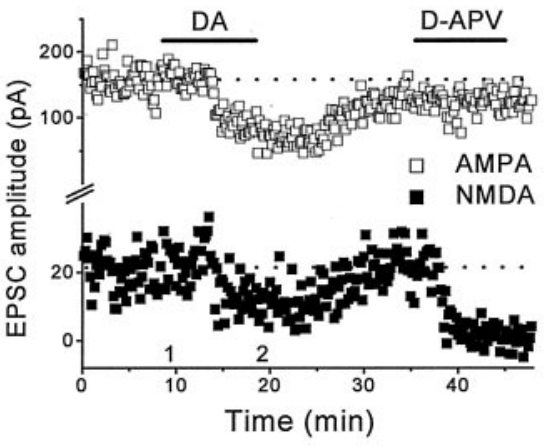

B Whole-cell NAc

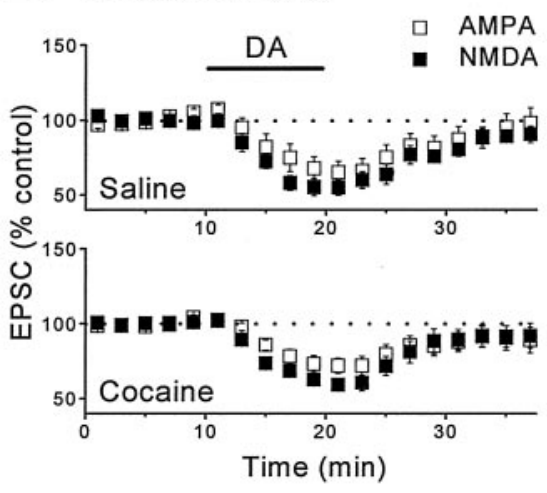

Whole-cell Striatum

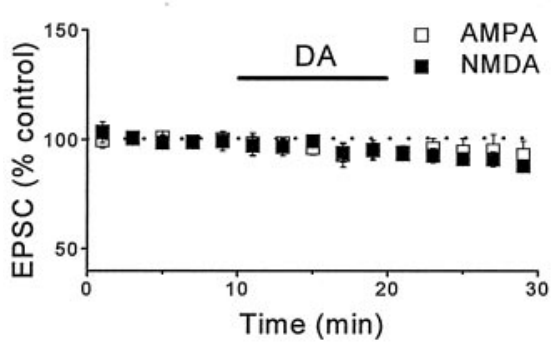

$\mathrm{A}_{2}$
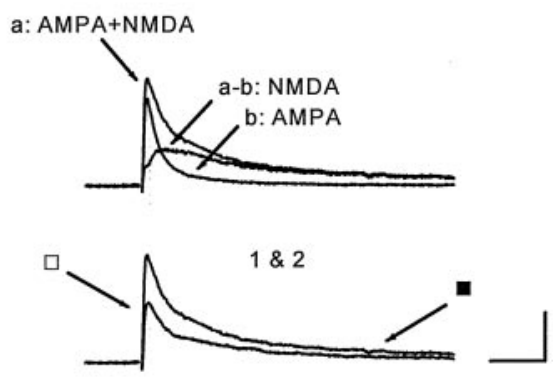

C Perf.-patch NAc

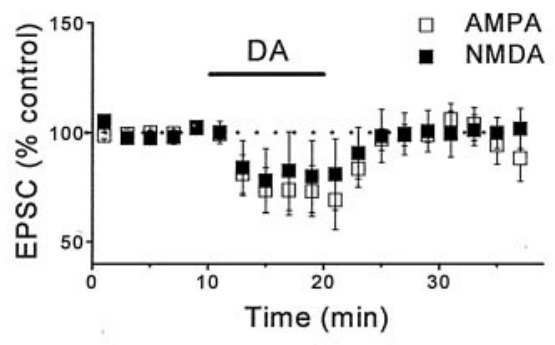

$E$

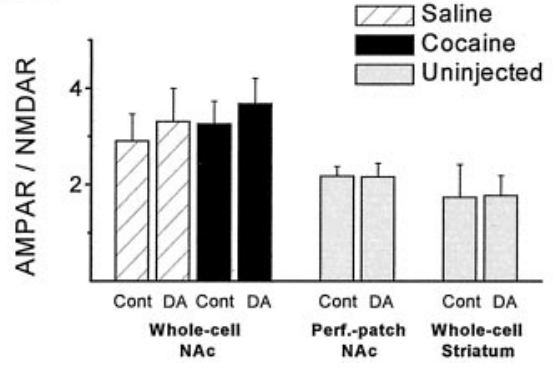

Figure 4. DA does not potentiate NMDAR EPSCs in either the NAc or dorsal striatum. $A 1$, Example of an experiment in which DA $(75 \mu \mathrm{M})$ was applied while simultaneously monitoring AMPAR EPSCs and NMDAR EPSCs at $+40 \mathrm{mV}$. Note that application of D-APV $(50 \mu \mathrm{M})$ had minimal effect on the measurement of the AMPAR EPSC but eliminated the NMDAR EPSC. A2, Top traces show the dual-component EPSC, the AMPAR EPSC obtained after application of D-APV, and the NMDAR EPSC obtained by subtraction of the two traces. Bottom traces show the dual-component EPSC before and after application of DA. Arrows show time points at which measurements were made. Calibration: $50 \mathrm{msec}, 100 \mathrm{pA}$. B, Summary graph of the effects of DA $(75 \mu \mathrm{M})$ on NMDAR EPSCs and AMPAR EPSCs in saline ( $n=8$ cells, 5 mice) and cocainetreated ( $n=15$ cells, 9 mice) mice. $C$, Summary graph of the effects of DA $(100 \mu \mathrm{M})$ on NMDAR EPSCs and AMPAR EPSCs recorded in slices from control mice using perforated-patch recording techniques $(n=5$ cells, 4 mice). $D$, Summary graph of the effects of DA $(30-75 \mu \mathrm{M})$ on NMDAR EPSCs and AMPAR EPSCs in dorsal striatum slices from control mice ( $n=4$ cells, 4 mice). $E$, Mean AMPAR/NMDAR ratio during baseline and at the end of DA application for experiments shown in $B-D$. In all cases, DA did not affect the AMPAR/NMDAR ratios.
EPSC might obscure a direct postsynaptic effect of DA on NMDAR EPSCs. It is also conceivable that the strong depolarization of the cells caused them to release some substance that obscured this effect of DA. However, to account for our results, such an action must have lasted $>10 \mathrm{~min}$, because we routinely obtained a minimum of a $10 \mathrm{~min}$ baseline before applying DA.

The functional significance of the enhancement of the inhibitory synaptic actions of DA in the NAc shell after chronic in vivo cocaine exposure remains to be determined. We would suggest it is likely one of a number of modifications of synaptic and cellular function in the NAc contributing to behavioral sensitization. Interestingly, many of the reported effects of chronic in vivo cocaine exposure would be expected to decrease net excitatory drive to medium spiny neurons (Henry and White, 1991; White et al., 1995; White and Kalivas, 1998; Wolf, 1998; Thomas et al., 2001), an action that might sensitize the rewarding or incentive value of drugs of abuse (Wise, 1998; Robinson and Berridge, 2000).

\section{REFERENCES}

Calabresi P, Mercuri N, Stanzione P, Stefani A, Bernardi G (1987) Intracellular studies on the dopamine-induced firing inhibition of neostriatal neurons in vitro: evidence for D1 receptor involvement. Neuroscience 20:757-771.

Calabresi P, De Murtas M, Pisani A, Stefani A, Sancesario G, Mercuri NB, Bernardi G (1995) Vulnerability of medium spiny striatal neurons to glutamate: role of $\mathrm{Na}+/ \mathrm{K}+$ ATPase. Eur J Neurosci 7:1674-1683.

Cepeda C, Buchwald NA, Levine MS (1993) Neuromodulatory actions of dopamine in the neostriatum are dependent upon the excitatory amino acid receptor subtypes activated. Proc Natl Acad Sci USA 90:9576-9580.

Cepeda C, Colwell CS, Itri JN, Chandler SH, Levine MS (1998) Dopaminergic modulation of NMDA-induced whole cell currents in neostriatal neurons in slices: contribution of calcium conductances. J Neurophysiol 79:82-94.

Civelli O, Bunzow JR, Grandy DK (1993) Molecular diversity of the dopamine receptors. Annu Rev Pharmacol Toxicol 33:281-307. 
Groenewegen HJ, Wright CI, Beijer AV, Voorn P (1999) Convergence and segregation of ventral striatal inputs and outputs. Ann NY Acad Sci 877:49-63.

Harvey J, Lacey MG (1996) Endogenous and exogenous dopamine depress EPSCs in rat nucleus accumbens in vitro via D1 receptor activation. J Physiol (Lond) 492:143-154.

Harvey J, Lacey MG (1997) A postsynaptic interaction between dopamine D1 and NMDA receptors promotes presynaptic inhibition in the rat nucleus accumbens via adenosine release. J Neurosci 17:5271-5280.

Henry DJ, White FJ (1991) Repeated cocaine administration causes persistent enhancement of D1 dopamine receptor sensitivity within the rat nucleus accumbens. J Pharmacol Exp Ther 258:882-890.

Higashi H, Inanaga K, Nishi S, Uchimura N (1989) Enhancement of dopamine actions on rat nucleus accumbens neurones in vitro after methamphetamine pre-treatment. J Physiol (Lond) 408:587-603.

Jarvie KR, Caron MG (1993) Heterogeneity of dopamine receptors. Adv Neurol 60:325-333.

Kalivas PW, Duffy P (1993) Time course of extracellular dopamine and behavioral sensitization to cocaine. I. Dopamine axon terminals. J Neurosci 13:266-275.

Levine MS, Li Z, Cepeda C, Cromwell HC, Altemus KL (1996) Neuromodulatory actions of dopamine on synaptically-evoked neostriatal responses in slices. Synapse 24:65-78.

Martin G, Ahmed SH, Blank T, Spiess J, Koob GF, Siggins GR (1999) Chronic morphine treatment alters NMDA receptor-mediated synaptic transmission in the nucleus accumbens. J Neurosci 19:9081-9089.

Nicola SM, Malenka RC (1997) Dopamine depresses excitatory and inhibitory synaptic transmission by distinct mechanisms in the nucleus accumbens. J Neurosci 17:5697-5710.

Nicola SM, Malenka RC (1998) Modulation of synaptic transmission by dopamine and norepinephrine in ventral but not dorsal striatum. J Neurophysiol 79:1768-1776.

Nicola SM, Kombian SB, Malenka RC (1996) Psychostimulants depress excitatory synaptic transmission in the nucleus accumbens via presynaptic D1-like dopamine receptors. J Neurosci 16:1591-1604.

Nicola SM, Surmeier J, Malenka RC (2000) Dopaminergic modulation of neuronal excitability in the striatum and nucleus accumbens. Annu Rev Neurosci 23:185-215.

O'Donnell P, Grace AA (1994) Tonic D2-mediated attenuation of cortical excitation in nucleus accumbens neurons recorded in vitro. Brain Res 634:105-112.

Pennartz CM, Dolleman-Van der Weel MJ, Kitai ST, Lopes da Silva FH
(1992) Presynaptic dopamine D1 receptors attenuate excitatory and inhibitory limbic inputs to the shell region of the rat nucleus accumbens studied in vitro. J Neurophysiol 67:1325-1334.

Pierce RC, Kalivas PW (1995) Amphetamine produces sensitized increases in locomotion and extracellular dopamine preferentially in the nucleus accumbens shell of rats administered repeated cocaine. J Pharmacol Exp Ther 275:1019-1029.

Robinson TE, Berridge KC (1993) The neural basis of drug craving: an incentive-sensitization theory of addiction. Brain Res Brain Res Rev 18:247-291.

Robinson TE, Berridge KC (2000) The psychology and neurobiology of addiction: an incentive-sensitization view. Addiction 95 [Suppl 2]:S91-S117.

Robinson TE, Jurson PA, Bennett JA, Bentgen KM (1988) Persistent sensitization of dopamine neurotransmission in ventral striatum (nucleus accumbens) produced by prior experience with $(+)$-amphetamine: a microdialysis study in freely moving rats. Brain Res 462:211-222.

Sibley DR, Monsma Jr FJ (1992) Molecular biology of dopamine receptors. Trends Pharmacol Sci 13:61-69.

Thomas MJ, Beurrier C, Bonci A, Malenka RC (2001) Long-term depression in the nucleus accumbens: a neural correlate of behavioral sensitization to cocaine. Nat Neurosci 4:1217-1223.

Uchimura N, North RA (1991) Baclofen and adenosine inhibit synaptic potentials mediated by $\gamma$-aminobutyric acid and glutamate release in rat nucleus accumbens. J Pharmacol Exp Ther 258:663-668.

Vanderschuren LJ, Kalivas PW (2000) Alterations in dopaminergic and glutamatergic transmission in the induction and expression of behavioral sensitization: a critical review of preclinical studies. Psychopharmacology (Berl) 151:99-120.

White FJ, Kalivas PW (1998) Neuroadaptations involved in amphetamine and cocaine addiction. Drug Alcohol Depend 51:141-153.

White FJ, Hu X-T, Zhang X-F, Wolf ME (1995) Repeated administration of cocaine or amphetamine alters neuronal responses to glutamate in the mesoaccumbens dopamine system. J Pharmacol Exp Ther 273:445-454.

Wise RA (1998) Drug-activation of brain reward pathways. Drug Alcohol Depend 51:13-22.

Wolf ME (1998) The role of excitatory amino acids in behavioral sensitization to pyschomotor stimulants. Prog Neurobiol 54:679-720.

Zahm DS (1999) Functional-anatomical implications of the nucleus accumbens core and shell subterritories. Ann NY Acad Sci 877:113-128. 